\title{
VÍRUS ZIKA E MICROCEFALIA: \\ A MÃE FRENTE AO DIAGNÓSTICO DO FILHO
}

\author{
VIRUS ZIKA AND MICROCEFALIA: \\ THE MOTHER FACES THE DIAGNOSIS OF THE SON
}
lago Pereira Nascimento' Renara Meira Gomes ${ }^{2}$ Sheylla Nayara Sales Vieira ${ }^{3}$ Tarciso Pereira Guedes ${ }^{4}$ Geovana De Jesus Santana 5 Francine Neves Silva ${ }^{6}$

\section{RESUMO}

Objetivo: verificar quais os sentimentos vivenciados pelas mães diante o diagnóstico de microcefalia do filho e as estratégias de enfrentamento utilizadas. Metodologia: para alcançar os resultados, foi utilizada a pesquisa de campo com sete mães, cujos filhos estavam matriculados na APAE - Jequié/BA. Para a coleta de dados utilizou-se a entrevista semiestruturada composta por questões sociodemográficas e objetivas sobre o tema. Empregou-se a técnica do Discurso do Sujeito Coletivo para análise de dados. Resultados: diante o diagnóstico de deficiência do filho as mães vivenciam sentimentos predominantemente negativos caracterizando-se em um lento e doloroso luto, uma vez que o filho idealizado durante a gestação foi substituído por um filho enfermo, causando grande choque de realidade. As estratégias de enfrentamento utilizadas foram o coping religioso, a busca por informações a cerca da deficiência e a busca por cuidados a criança na medicina. Com a responsabilidade de proporcionar bem-estar para as crianças, as mães sentem-se sobrecarregadas, pois se tornam as principais cuidadoras. Conclusão: fica evidente a importância na adoção de medidas de prevenção à saúde mental das mães e não somente para a criança afetada, pois a cuidadora é geralmente a mais atingida e essas dificuldades e frustrações, se não trabalhadas, poderão, também interferir no ajustamento social e desenvolvimento da criança. Essa é, portanto, uma questão que precisa ser discutida, a fim de que sejam desenvolvidas políticas públicas de assistência e atenção às cuidadoras.

Palavras-chave: Vírus Zika. Microcefalia. Mãe. Luto. Deficiência.

\footnotetext{
1 Graduado em Psicologia pela Faculdade de Tecnologia e Ciências (FTC). E-mail: i.ago_014@hotmail.com 2 Graduada em Enfermagem pela Faculdade de Tecnologia e Ciências (FTC). E-mail: nara_rhema@hotmail.com 3 Doutoranda em Enfermagem e Saúde pela Universidade Estadual do Sudoeste da Bahia. Coordenadora de pesquisa e extensão da Faculdade de Tecnologia e Ciências (FTC). E-mail: enfsheylla@gmail.com 4 Especialista em Neuropsicologia. Graduado em Psicologia. Docente da Faculdade de Tecnologia e Ciências (FTC). E-mail: tguedes.jeq@ftc.edu.br

5 Graduada em Enfermagem pela Faculdade de Tecnologia e Ciências (FTC). E-mail: geoenfermeira@hotmail.com 6 Graduada em Enfermagem pela Faculdade de Tecnologia e Ciências (FTC). E-mail: aneneves12@hotmail.com
} 


\section{ABSTRACT}

Objective: to verify the feelings experienced by mothers regarding the diagnosis of the child's microcephaly and the coping strategies used. Methodology: to reach the results, field research was used with seven mothers, whose children were enrolled in APAE - Jequié / BA. For the data collection, a semistructured interview was made up of sociodemographic and objective questions about the subject. The technique of Collective Subject Discourse was used for data analysis. Results: in the face of the diagnosis of the child's disability, mothers experience predominantly negative feelings, characterized by a slow and painful mourning, since the idealized child during pregnancy was replaced by a sick son, causing a great shock of reality. The coping strategies used were religious coping, the search for information about disability and the search for child care in medicine. With the responsibility of providing well-being for children, mothers feel overwhelmed as they become the primary caregivers. Conclusion: The importance of adopting preventive measures to mothers' mental health is evident, and not only to the affected child, because the caregiver is usually the most affected and these difficulties and frustrations, if not worked, can also interfere in the social adjustment and development of the child. This is, therefore, an issue that needs to be discussed, in order to develop public policies of care and attention to caregivers.

Keywords: Zika virus. Microcephaly. Mother. Mourning. Disability.

\section{INTRODUÇÃO}

É verdade que nem toda mulher deseja ser mãe, por outro lado a maternidade constitui-se o ápice da realização pessoal para a maioria das mulheres, mas o processo gestacional traz sempre consigo alterações biológicas e psicológicas, tornando a gravidez uma experiência complexa e particular para cada mulher, processo este que mobiliza também a família e o meio em que está inserida (SANTOS et al., 2010). Durante esse processo a mulher está vulnerável a doenças que podem afetar a saúde do bebê (BARROS, 2006).

A epidemia do vírus Zika, transmitido pelos mosquitos Aeds aegyptie e o Aedes albopictus, tem, portanto marcado a vida de muitas mulheres brasileiras provocando nas gestantes sentimentos de medo, apreensão e insegurança (NELVO, 2016; BRASIL, 2018).

De acordo com o Ministério da Saúde, a infecção pelo vírus Zika durante a gravidez está relacionada com as malformações neurológicas, como a microcefalia, que é definida como uma má formação neonatal. A criança acometida apresenta a medida encefálica muito menor que outras crianças da mesma idade e sexo 
e o crescimento cerebral insuficiente. Estes aspectos vêm acompanhados de deficiências no desenvolvimento, podendo ser de leve a grave (BRASIL, 2015).

Desde o inicio da epidemia do vírus Zika em 2015, já foram confirmados no Brasil o nascimento de aproximadamente dois mil bebês com microcefalia e outras alterações do sistema nervoso, resultantes da infecção pelo vírus (FIOCRUZ, 2017).

A chegada de um bebê com malformação congênita produz, portanto, a quebra no processo de idealização do nascimento de um bebê saudável, surgindo assim sentimentos negativos (ROECKER et al., 2012). Se o filho tão esperado e idealizado nasce "imperfeito", este interrompe os sonhos da mãe trazendo uma realidade que pode provocar um choque. O filho perfeito idealizado é, então, substituído por um ser real, enfermo, provocando uma ruptura nos planos idealizados (MANNONI, 1999; NAVE, 2013).

Com a responsabilidade de proporcionar bem-estar para as crianças, as mães sentem-se sobrecarregadas, pois se tornam as principais cuidadoras. Esse processo exige, a depender dos níveis de incapacidade da criança, atenção e cuidados redobrados, provocando desgastes físicos e emocionais (PINTO et al., 2014; CARVER, 2010).

Tendo em vista os grandes índices de ocorrências de nascimentos de bebês microcefálicos correlacionados ao surto do vírus Zika atualmente no Brasil, surgiu o seguinte questionamento: quais os efeitos/sentimentos vivenciados e sofridos pelas mães ao receberem o diagnóstico de microcefalia no filho?

Assim, o objetivo desta pesquisa foi identificar quais os sentimentos vivenciados pelas mães diante o diagnóstico de microcefalia do filho e as estratégias de enfrentamento utilizadas.

\section{METODOLOGIA}

Trata-se de uma pesquisa de campo, de um estudo descritivo, exploratório (FONSECA, 2002). Sua abordagem é qualitativa, pois a mesma se atenta à subjetividade, aos significados das ações e das relações humanas não podendo estes serem observados através de dados estatísticos (MINAYO, 2001).

Foram sujeitos dessa pesquisa sete mães cujos filhos foram diagnosticados com microcefalia e que estão matriculados na APAE Jequié-BA, município localizado no nordeste brasileiro. A busca foi realizada no banco de dados da APAE, onde foram identificados onze casos de microcefalia, dentre eles apenas sete mães se disponibilizaram para a entrevista.

Utilizou-se a entrevista semiestruturada que é composta pela coleta dos dados de maneira objetiva, com busca de informações pessoais das crianças e das mães; e subjetiva, que procura investigar através das falas o conhecimento das mães sobre Zika e microcefalia e os sentimentos das mães em relação ao filho microcefálico, aspecto que se compõe na essência deste trabalho. As entrevistas 
semiestruturadas tornaram possível uma abordagem mais livre do tema proposto (MINAYO, 2001).

As entrevistas foram realizadas no período de julho a setembro de 2017. Os encontros foram agendados com as mães por telefone e aconteceram na APAE e na própria residência, de acordo com a escolha da entrevistada. As entrevistas só foram realizadas após as assinaturas dos termos de consentimento livre e esclarecido por ambas as partes, mães e pesquisador, onde foi acordado total sigilo de identidade da mãe e criança. A participação foi voluntária, tendo sido informado às mães os objetivos da pesquisa e o uso dos dados coletados.

Após as entrevistas, os conteúdos das falas foram transcritos e analisados com base no método do Discurso do Sujeito Coletivo (DSC), onde as expressões que apresentam sentidos semelhantes são agrupadas em categorias gerais "de modo a formar com tais conteúdos um depoimento síntese, redigido na primeira pessoa do singular, como se tratasse de uma coletividade falando na pessoa de um indivíduo" (LEFEVRE; LFEVRE, 2014; GOMES et al, 2018).

Com a finalidade de preservar o anonimato das participantes, as mesmas não tiveram seus nomes identificados. Por se tratar de uma pesquisa realizada com seres humanos, tornou-se necessário que os princípios éticos fossem assegurados, visando defender a integridade dos sujeitos pesquisados, sendo aprovado pelo comitê de ética em pesquisa CEP da Universidade Estadual da Bahia, preceito da Resolução n 466/12 do Conselho Nacional da Saúde (BRASIL, 2012).

\section{RESULTADOS}

Participaram dessa pesquisa sete mães com idades compreendidas entre 23 e 35 anos, dentre as quais cinco eram casadas. Dessas, três possuem outro filho além da criança com necessidades especiais.

Os sentimentos vivenciados por mães que possuem filhos portadores de microcefalia permitiram a construção de discursos coletivos onde está expresso o entendimento do processo diante o diagnóstico de microcefalia. A seguir apresentamos cada Discurso do Sujeito Coletivo (DSC) e discutimos tais discursos.

\section{DSC 01}

\section{Ideia central - O choque diante da realidade}

Parei no tempo, eu fiquei, em estado de choque, fiquei com depressão dentro de casa, não pensava mais em nada, só nela. No inicio tomei um choque, porque nunca tinha ouvido falar sobre microcefalia, ate eu entender, me acostumar, fiquei um tempão abalada, agora acostumei já, já sei a diferença de uma e do outro. 
Assustada, os médicos queriam que eu abortasse, mas eu e meu esposo não aceitamos. Fiquei "meia" paralisada, é difícil.

Dados da pesquisa. Jequié-2017

O DSC 01 apresenta os primeiros sentimentos das mães diante do diagnóstico de microcefalia. Deixa evidente que o primeiro sentimento vivenciado por essas mães foi o choque emocional diante de uma realidade que elas não tinham conhecimento e se quer cogitavam a possibilidade.

Além do choque emocional, as mães relataram um estado depressivo, no qual buscaram o isolamento como refúgio para enfrentar esse momento de angústia. No entanto, o discurso também apresenta que embora vivenciando uma situação adversa, é possível perceber o desejo em dar continuidade ao processo de ser mãe, buscando alternativas de adaptação a essa realidade.

DSC 02

Ideia central - Tristeza, Angústia e Coping religioso

Na verdade foi uma mistura de sentimentos, decepção, tristeza. Tristeza, nunca esperava acontecer com a gente, até hoje não aceito. Foi um momento muito doloroso, porque ate então eu não conhecia o que era a microcefalia, e sim a hidrocefalia que era mais comum a gente ouvir e quando fui pesquisar na internet tomei um susto, e sendo assim crendo que Deus ira entrar com providencia em tudo.

Dados da pesquisa. Jequié-2017.

O DSC 02 deixa evidente as angústias vivenciadas pelas mães. Estas relatam diversos sentimentos, o que pode ser compreensível, pois com o diagnóstico de microcefalia, o ideal de filho perfeito construído se perde. Isso traz à tona uma realidade desconfortável e ameaçadora, na qual a mãe vê seus sonhos e planos projetados serem desfeitos, precisando esta se readaptar à nova realidade.

A angústia diante dessa dolorosa realidade expressada pelas mães deixa claro o sentimento de raiva e decepção. Esses sentimentos, porém, também são direcionados para si, por sentirem-se culpadas pela gestação de uma criança deficiente. Ao vivenciar essa experiência, as mães se deparam com o desconhecimento e a desinformação acerca da microcefalia, o que significa que as mesmas não saberão a princípio nortear suas atitudes. 
É possível, também, perceber no discurso das mães a necessidade de buscar respostas do ponto de vista espiritual para o problema, encontrando na religião auxílio para o enfrentamento e aceitação.

O questionamento sobre as estratégias de enfrentamento desenvolvidas pelas mães, diante da microcefalia, permitiu a construção de dois discursos que mostram que, mesmo inconformados com as restrições e impossibilidades dos seus filhos elas não desistem de buscar soluções, sejam elas através da fé ou por meio de métodos humanos.

\title{
DSC 03
}

\section{Ideia central - A busca por melhores condições de vida para a criança e informações sobre a microcefalia}

\begin{abstract}
Ajudar a criança, ir a Salvador, em Jequié e em Ipiaú, na verdade Itagiba onde eu moro. Procurar fazer a fisioterapia de segunda à sexta, e a gente procura fazer assim o máximo que a medicina oferece e crendo que ele vai ter uma vida saudável. Assim, tem coisa que eu penso em fazer assim, mas tem coisa que não da certo, ai agente da um jeitinho, tudo o que eu posso. Levar ele nos médicos, para melhorar, eu quero que ele seja um adolescente normal. A cada dia procuro me informar mais sobre a doenç
\end{abstract}

Dados da pesquisa. Jequié-2017

O DSC 03 possibilita entender a continuação do cuidado da mãe para com a criança, mesmo essa não sendo o filho sonhado. Uma das estratégias utilizadas é a inserção da criança no tratamento que é oferecido pelo sistema único de saúde. Pode-se observar no discurso as dificuldades encontradas por algumas mães nesse processo, pois nem sempre os serviços necessários estão disponíveis na cidade onde residem, tendo que se deslocarem a outras cidades. Essa rotina pode contribuir para um maior desgaste físico e emocional.

A busca por informações no que infere a deficiência da criança também são estratégias utilizadas pelas mães, que buscam na medicina uma esperança para a melhoria da criança.

\section{DSC 04}

Ideia central - Fé e esperança em dias melhores

Pelos olhos humanos a gente sabe que a microcefalia ela não tem cura, porém ela tem paliativo. Primeiro minha fé em Deus e depois busco tudo que é possível para ela. Agora no meu ponto de vista,

\section{INTER/SCIENTIA}

REVISTA INTERSCIENTIA | V. 7 | N. 1 | P. 54-65 | JAN-JUN/2019 
eu ergo a cabeça e tenho que seguir com ela, minha filha é uma criança normal para mim.

Dados da pesquisa. Jequié-2017

No DSC 04, evidenciam-se, que apegar-se a uma religião ou crenças são estratégias adotadas simultaneamente no enfrentamento de uma situação específica para auxiliar na elaboração psíquica das repercussões de uma condição estressora, como a malformação congênita.

O discurso coletivo evidencia que as mães acreditam que mesmo o filho tendo limitações severas, em virtude do diagnóstico, Deus pode fazer um milagre e reverter o diagnostico. O coping religioso é, portanto, uma estratégia utilizada para manejar as situações estressantes.

\section{DISCUSSÃO}

Os discursos apresentados pelas mães são permeados por sentimentos predominantemente negativos que, com o impacto da notícia, ficam desorientadas, impotentes e desamparadas diante do desconhecido. O filho imaginário agora é substituído por um filho real e diferente do idealizado durante todo processo gestacional, frustrando às suas expectativas.

Desde o pré-natal, é construída a relação mãe-bebê, carregada de expectativas e sonhos da genitora para com ele. Toda mãe espera uma criança perfeita e, se a mesma nasce com alguma deficiência, terá que aceitar, em seu lugar, aquilo que não foi projetado, muito menos desejado e que frustrou suas expectativas (PICCININI et al., 2008).

Percebe-se nas falas das mães que a busca pelo filho "normal", vem como uma ideia construída historicamente e culturalmente. Quando se fala em ter um filho com microcefalia, ao receberem a notícia, as mães podem sentir choque, raiva, medo, tristeza, ansiedade, somatização, pensamentos intrusivos, dentre outros (OSÓRIO; VALE, 2009).

O DSC 01 apresenta, o choque como primeiro sentimento identificado, após o recebimento da notícia de deficiência do filho. A reação aguda ao estresse também conhecida como choque psíquico, ou estado de choque, é uma interrupção violenta dos estados emocionais habituais que provoca um desequilíbrio emocional (KAPCZINSKI; MARGIS, 2003).

A invasão da dolorosa realidade provoca um choque na mãe, pois as fantasias de um filho imaginário e perfeito são substituídas por um ser real e enfermo. O nascimento do filho ocupa um lugar em meio aos seus sonhos perdidos, tendo a missão de restabelecer e reparar o que no percurso de vida da mãe foi julgado deficiente e que se deu como falta. Portanto, não será capaz de suprir 
suas expectativas, restaurando assim, os traumas e os desprazeres (MANNONI, 1999; FREUD, 1996; SANDERS, 1999).

As mães, através dos discursos, demonstram seus filhos como uma forma de dar seguimento a sua própria vida, bem como uma possibilidade de dar novos significados a ela. Portanto, tomar consciência dessa realidade traz para a mãe uma profunda tristeza, que podemos observar no DSC 02, vivendo, pois, um conflito existencial e emocional.

Esse estado, que é na verdade apenas sintoma do luto, tende a permanecer durante a fase de aceitação da deficiência da criança. No entanto, se não há a elaboração desse luto, é possível que a mãe passe deste para um processo de depressão. Não havendo a ausência material, o luto se abriga diante de um morrer estranho (CAVALCANTI, 2013).

A depressão pode ser, portanto, compreendida como uma das fases do luto. Tristeza, desesperança e medo, levam à mãe a um sofrimento profundo. Nesse momento, começa a tomar consciência da sua atual condição, sentindo uma necessidade de isolamento, no qual acontecerá uma grande introspecção. Assim, ela percebe que nada do que foi feito ou tentou fazer resolveu o seu problema, surgindo um sentimento de grande perda (CAVALCANTI, 2013).

São compreensíveis os momentos de profunda dor, rejeição, não aceitação, decepção, tristeza e medo vivenciados pelas mães ao se depararem com a notícia de deficiência do filho. No entanto, não se pode ignorar o quanto é extremamente prejudicial para o desenvolvimento da criança. Por um lado, vê-se uma mãe que precisa adaptar-se a uma nova realidade e, por outro, uma criança que aguarda esse tempo, esperando ser atendido e ter suas necessidades supridas (PANZINI, 2007).

Uma mãe depressiva não é capaz de oferecer à criança o suporte e o amor objetal capazes de suprir suas necessidades. A mãe intervém como ativa construtora do espaço mental da criança. Espera-se da mãe, portanto, uma maternagem suficientemente boa, assim, garantindo que o desenvolvimento do bebê ocorra de forma adequada (SILVA, 2016).

Depois de experimentarem períodos muito difíceis, as mães começam a aceitar a realidade e enfrentá-la, com consciência das suas possibilidades e limitações (CAVALCANTI, 2013). Quando a mãe consegue um equilíbrio dos sentimentos, pode, finalmente, organizar-se e ocupar-se dos cuidados necessários para o seu bebê.

A busca por cuidados à criança pode ser vista no DSC 03, em que as mães procuram auxílio através da medicina para proporcionar melhor qualidade de vida para a criança. Embora busquem acessar fontes de apoio representadas pelos profissionais de saúde, não encontram o suporte necessário. Assim, a mãe vai vencendo pouco a pouco a deficiência do filho, buscando um relacionamento 
de amor e cuidado, superando seus desejos, como mãe, de ver seu filho como qualquer outra criança, uma criança saudável.

Foi possível identificar também que a espiritualidade, como aponta a literatura é uma estratégia utilizada para enfrentar os momentos difíceis. O DSC 04 mostra que, em meio à aflição, emerge a necessidade de acreditar em uma força superior, buscando na religião auxílio para conseguir compreender e aceitar sua realidade, característica que pode-se observar também no DSC 03.

Voltar-se à religião, para lidar com os problemas que acontecem no dia-a-dia, pode ser entendido como coping religioso-espiritual (CRE). Segundo Silva e colaboradores (2016), a espiritualidade é utilizada como uma forma de enfrentamento da situação.

O coping religioso-espiritual, como forma de enfrentamento para essa condição estressora, que é ter um filho com malformação congênita, pode, portanto, trazer equilíbrio psicológico, emocional e bem-estar físico (TARAKESHWAR; PARGAMENT, 2001, ROSS, 2017).

As crianças microcefálicas podem ter graves consequências, como o atraso mental, déficit intelectual, paralisia, rigidez dos músculos, entre outros problemas. De fato, estes terão que viver em estado de completa vigilância e cuidados diários. A mãe, por se tornar a principal cuidadora, na maioria das vezes, acaba privandose de viver sua própria vida em prol do seu filho.

Vê-se uma constante busca a fim de favorecer a criança, enquanto a mãe não encontra apoio para enfrentamento do problema, tendo esta que encarar sozinha a sobrecarga física e emocional da sua realidade. O Estado é o maior responsável por lidar com a epidemia do vírus zika e os consequentes casos de microcefalia. No entanto, não há auxílio direcionado para as mães e sim apenas para a criança. Faz-se necessário um olhar mais humanizado para as genitoras, garantindo a elas um suporte psicológico.

A mãe, que passa por esse processo de luto, pode sim receber auxílio, como uma intervenção psicológica, que possa amparar esse sujeito repleto de questionamentos, anseios e culpas. O acompanhamento psicológico pode ser útil para a vivência das fases do luto: negação, raiva, barganha, depressão e aceitação (TARAKESHWAR; PARGAMENT, 2001; SANDERS, 1999).

Nessa perspectiva, o psicólogo pode agir como mediador no processo de enfrentamento da doença, possibilitando a criação de um espaço de troca de experiências, conhecimentos e sentimentos entre as mães. Dessa forma, poderá motivar uma melhor expressão das emoções e promover o bem estar do cuidador, familiares e até mesmo da criança.

O psicólogo pode promover um espaço de amparo à mãe, no qual a mesma possa desenvolver suas potencialidades, sejam elas no enfrentamento ou no relacionamento com o bebê. A Psicologia tem um papel importante nesse momento e deve atuar desde a gestação junto à mãe e a equipe multidisciplinar. 


\section{CONSIDERAÇÕES FINAIS}

O estudo evidencia a experiência vivenciada pelas mães, diante do processo de diagnóstico do filho, que representa no primeiro momentos de muita tristeza e angústia. Percebeu-se que a chegada de um filho microcefálico quebra todas as expectativas e sonhos construídos durante a gestação, provocando grande choque de realidade para as mães. Elas sofrem esse processo de forma mais ativa, principalmente pelo fato de se sentirem responsáveis pela gestação.

A presença de sentimentos negativos nas mães podem se estabelecer como perigo para o equilíbrio emocional e também para o desenvolvimento integral da criança, pois se espera da mãe, uma maternagem que venha suprir todas as necessidades biológicas e psicológicas.

Diante disso, é notório que as mães precisam ser assistidas, ajudadas, orientadas, e compreendidas, para que possam ajustar-se e realizar satisfatoriamente a sua função materna. Fica evidente a importância na adoção de medidas de prevenção à saúde mental das mães.

Tais discursões devem ser ampliadas, a fim de que sejam desenvolvidas políticas públicas de assistência e atenção às mães, enquanto cuidadoras, com implantação de uma rede de apoio às famílias, que comtemplem não apenas a saúde mental, como também outros aspectos fundamentais, garantindo assistência integral.

Acreditamos que as conclusões apontadas sejam de grande valor para os profissionais de saúde, visto que, diante tal situação, a mãe contará com o apoio de uma equipe multidisciplinar, incluindo fisioterapeutas, terapeutas ocupacionais, assistentes sociais, médicos, psicólogos e enfermeiros, ou seja, toda uma equipe multidisciplinar. Estes necessitarão estar também dispostos para lidar com as angústias, dúvidas, sofrimentos e medos das mães.

Os enfermeiros, por participarem do processo pré e pós-natal, com maior frequência precisam estar atentos e sensíveis à situação, realizando um trabalho em conjunto com os profissionais da saúde mental.

Cuidar da mãe em um momento tão desorientador é abrir espaços nos quais a mesma poderá expressar-se, sentir-se respeitada e assistida. É preciso, portanto, que os profissionais de saúde tenham essa mãe como um sujeito a ser cuidado, criando e recriando maneiras diferentes e personalizadas de estratégias para uma intervenção eficaz.

\section{REFERÊNCIAS}

BARROS, L. O Bebê Nascido em Situação de Risco. In: Canvarro, M. (Coord.), Psicologia da Gravidez e da Maternidade. 2a Edição. Coimbra: Quarteto, 2006. 
BRASIL. Ministério da Saúde. Conselho nacional de saúde. Comissão nacional de ética em pesquisa, 2012. Disponível em: <http://bvsms.saude.gov.br/bvs/saudelegis/ cns/2013/res0466_12_12_2012.html>. Acesso em : 9 de Out, 2018.

BRASIL. Ministério da Saúde. Protocolo de vigilância e resposta à ocorrência de microcefalia relacionada à infecção pelo vírus Zika, 2015. Disponível em: <http:// portalarquivos.saude.gov.br/images/pdf/2015/dezembro/09/ Microcefalia--Protocolo-de-vigila-ncia-e-resposta-vers--o-1----09dez2015-8h.pdf>. Acesso em: 10 Out. 2018.

CANAVARRO, M. C. Gravidez e Maternidade - representações e tarefas de desenvolvimento. In M. C. Canavarro (Ed.), Psicologia da Gravidez e da Maternidade. p. 17- 49. Coimbra: Quarteto. 2001.

CARVER, C. S.; CONNOR-SMITH, J. Personality and Coping. Annual Review of Psychology, v. 61, p. 679-704. 2010.

CAVALCANTI, A. K. S. et al. O conceito psicanalítico do luto: uma perspectiva a partir de Freud e Klein. Psicologia inf., v. 17, n. 17, p. 87-105, 2013.

FIOCRUZ. Fiocruz e Centro Internacional de Evidência em Deficiência coordenam projeto sobre Síndrome Congênita do Zika, 2017. Disponível em: <https://rededengue. fiocruz.br/noticias/585-fiocruz-e-centro-internacional-de-evidencia-em-deficienciacoordenam-projeto-sobre-sindrome-congenita-do-zika>. Acesso em: 10 Out. 2017.

FONSECA, J. J. S. Metodologia da pesquisa científica. Fortaleza: UEC, 2002. Disponível em: <http://leg.ufpi.br/subsiteFiles/lapnex/arquivos/files/Apostila_METODOLOGIA_ DA_PESQUISA(1).pdf> Acessado em : 11 de Nov. de 2018.

FREUD, S. A história do Movimento Psicanalítico, Artigos sobre a Metapsicologia e outros trabalhos (1914- 1916). Edição Standard Brasileira das Obras Psicológicas Completas de Sigmund Freud. Vol. XIV. Rio de Janeiro: Imago. p. 245-263, 1996.

GOMES, R. M. et al. Limites e desafios da comunicação efetiva para a segurança do paciente: um discurso coletivo. Revista Eletrônica Acervo Saúde, v. 10, n. 1, 2006$2012,2018$.

KAPCZINSKI, F.; MARGIS, R. Transtorno de estresse pós-traumático: critérios diagnósticos. Revista Brasileira Psiquiatria, v. 25, s. 1, p. 3-7, 2003.

LEFEVRE, F; LEFEVRE, A. M. C. Discurso Do Sujeito Coletivo: Representações Sociais E Intervenções Comunicativas. Texto Contexto Enfermagem, v. 23, n.2, p. 502-7, 2014. MANNONI, M. A criança retardada e a mãe. 5 Ed. São Paulo: Martins Fontes, 1999. 
MINAYO, M; C; S. Pesquisa Social. Teoria, método e criatividade. 18 ed. Petrópolis: Vozes, 2001. Disponível em: <http://www.faed.udesc.br/arquivos/id_submenu/1428/ minayo_2001.pdf> Acessado em 11 de Nov. 2017.

NAVE, A. C. O Processo de Luto em Worden. In A. Barbosa (Coord.). Olhares sobre o Luto. Lisboa: Faculdade de Medicina da Universidade de Lisboa, p. 53-65, 2013.

NELVO, R. V. Zika: Do sertão nordestino à ameaça global. $1^{a}$ ed. Rio de Janeiro: Civilização Brasileira. Revista Latinoamericana, 24: 246-254, 2016.

OSÓRIO, L. C.; VALLE, M. E. P. Manual de terapia familiar. Porto Alegre: Artmed, 2009. PANZINI, R. G.; BANDEIRA, D. R. Coping (enfrentamento) religioso/espiritual. Revista psiquiatria clínica, v. 34, supl. 1, p. 126-135, 2007.

PICCININI, C. A. et al. Gestação e a constituição da maternidade. Psicologia em Estudo, v. 13, n. 1, p. 63-72. 2008.

PINTO, M. B. et al. Significado do cuidado à criança deficiente com necessidades especiais: relato de mães. Revista Ciência cuidado e Saúde, v. 13, n. 3, p. 549-555, 2014

ROECKER, S. et al. A vivência de mães de bebês com malformação. Esc. Anna Nery, v. 16, n. 1, p. 17-26, 2012.

ROSS, E. K. Sobre a morte e o morrer. 10. Ed. São Paulo: Martins Fontes, 2017.

SANDERS, C. The Mourning After: dealing with adult bereavement. 2. ed. NewYork: JonhWiley \& Sons, 1999.

SANTOS, A. L. et al. Assistência Pré-Natal: Satisfação e Expectativas. Revista Rene, v.11, (Número Especial), p. 61 - 71, 2010.

SILVA, E. H. P. et al. Enfrentamento do pai frente à malformação congênita do filho antes e depois do nascimento. Estudos e Pesquisas em Psicologia, v.16, v. 1, p. 180$199,2016$.

SILVA, G. S. Do feto ao bebê: Winnicott e as primeiras relações materno-infantis. Psicologia Clínica, v. 28, n. 2, p. 29-54, 2016.

TARAKESHWAR, N.; PARGAMENT, K. I. Religious coping in families of children with autism. Focus on Autism and Other Developmental Disabilities, 16(4), p. 247-260. 2001.

Recebido em: 13/12/2018.

Aceito em: 27/02/2019. 